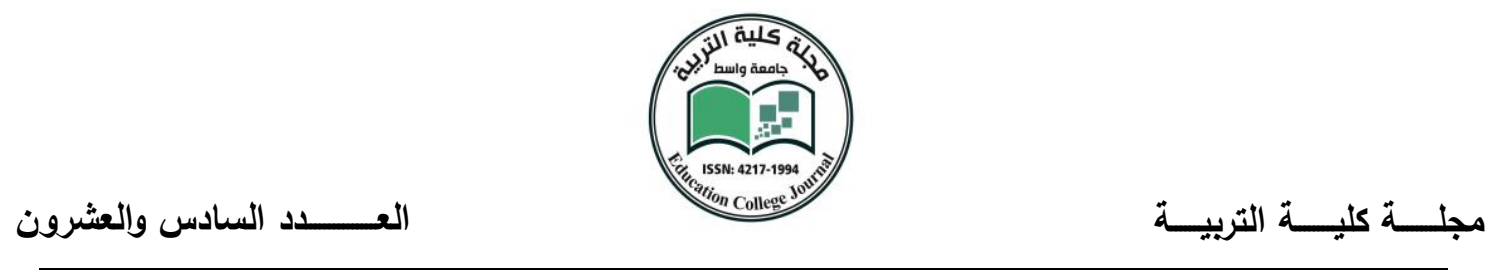

\title{
Moderated vs. Fossilized Modes of Teaching and Learning English in the Preparatory Classes in Iraq
}

\author{
Asst. Teacher: Abbas Idan Obaid
}

\begin{abstract}
The present study exhibits an outsight over the prominent problems that face the educational process and an outlook over the preparatory school syllabuses conducted in teaching English language in Iraq. Three syllabuses are to be concerned in the present study: the New English Course for Iraq (NECI), Iraq Opportunities (IO) and English for Iraq (EFI). The study propounds the main characteristics of each syllabus and their relativity to the variant approaches of teaching. The NECI conducted a classical mode of teaching, started with the sixties of the last century and continued until the year-study 2012-2013, for the sixth preparatory. English for Iraq, now replaced the "Iraq Opportunities", is taught for $4^{\text {th }}, 5^{\text {th }}$ and $6^{\text {th }}$ preparatory.

On the other hand, the study tackles the main problems that are also obstacles to teaching/learning progression in Iraq, such as those of using helping sketches diverting students from the syllabus trends and abolishing many learning activities. Iraq Opportunities proved to be better than the two other syllabuses, mainly in its being based on communicative method of teaching and more appropriate for teaching students in Iraq.
\end{abstract}

The educational system in Iraq, as the study recommends, needs more reforming, development and planning on the educational needs, at the variant levels of reliability. 


\section{Abbreviations}

CLT Communicative Language Teaching

EFI

English for Iraq

FL

Foreign Language

IO

$\mathrm{L} 2 \backslash \mathrm{SL}$

Iraq Opportunities

NECI

Second Language

PPP

New English Course for Iraq

SB

Presentation, Practice and Production

TBLT

Student's Book

Task Based Language Teaching

\section{Figures}

figure

page

Figure 1: A- A sample of helping sketches

Figure 1: B- A sample of helping sketches

Figure 2: A sample of reading comprehension, EFI Book 7.

SB. P. 67-8.

Figure 3: A sample drill from EFI, $5^{\text {th }}$ preparatory.

SB. p. 75.

Figure 4: A sample drill, $6^{\text {th }}$ preparatory, AB. P. 13.

Figure 5: A sample guided conversation, EFI, $5^{\text {th }}$ preparatory,

SB. P.6.

Figure 6: a task based drill, IO, SB, p. 69. 26

Figure 7 : A sample topic based lesson, IO, $4^{\text {th }}$ Preparatory.

SB. p. 14. 


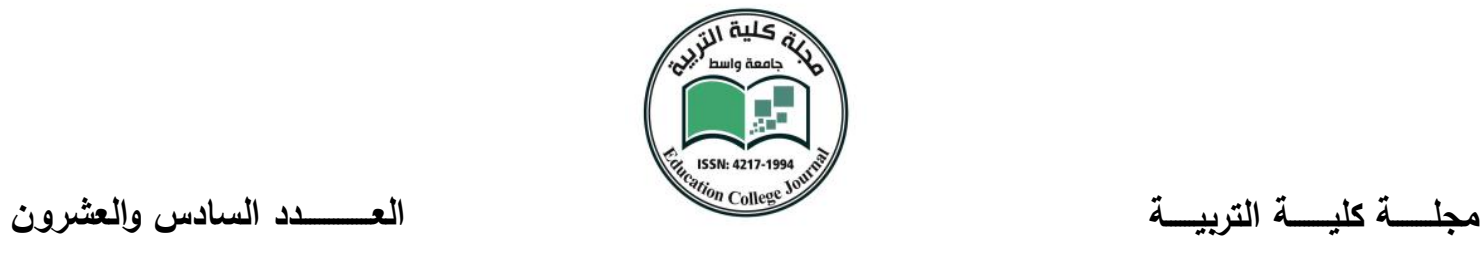

1- INTRODUCTION

\section{1-1 The Problem}

For many decades, the Iraqi curricula for teaching English remained undeveloped, suffering the abstention from the moderated modes and methods of teaching English language, which case affected the progress and ease of change in teaching English language.

Generally, most students in preparatory schools, for example, suffer their weakness in learning English and they have low marks and fail with more than one trial in passing their final stage of school. There could be many reasons for this case of which the helping sketches, the old fashioned methods of teaching and the diversity from the main objectives of the curriculum might be major factors for the retreat in the learning of English language.

The present study focuses on the extent to which the present curriculum of teaching English can achieve its objectives throughout the present circumstances and obstacles.

\section{1-2 The Aims of the Study}

The present study aims at:

a. Creating a comparison among the variant curricula taught in Iraq for the last two decades.

b. Specifying the main pitfalls that the former curriculum of English in preparatory school syllabus passed by, with reference to the role of the helping sketches in learning English.

c. Identifying the effects of using helping sketches in learning English by preparatory school students.

d. Showing the main difficulties which a teacher may face in teaching the new curriculum.

\section{1-3 The Hypotheses}

The present study hypothesizes that: 
a. "Iraq Opportunities" is more suitable for students than "English for Iraq" curriculum.

b. The helping sketches have a negative role and they work on abolishing the homework activities, adding to that they contain a lot of mistakes on variant linguistic levels and divert from the main objectives of the curriculum.

c. Preparatory school students need more explicit instruction in genre features, patterns and variations.

\section{1-4 The Procedures}

The following steps are to be followed in the present study.

a. Investigating the applicability of the variant syllabuses taught in Iraq, starting with " The New English Course For Iraq"

b. Investigating the extent to which the present curriculum is applicable for the communicative approach.

c. Comparing the variant curricula presented for teaching English in Iraq.

\section{1-5 The Limits}

The present study is limited to the methodological study of the preparatory curricula of English with comparison among syllabuses, including the "New English Course for Iraq", "English for Iraq" and "Iraq Opportunities".

\section{1-6 The Value of the Study}

It is hoped that the present study is helpful for the teachers of English in the preparatory schools.

\section{2- THEORETICAL BACKGOROUND 2-1- Methods of Teaching}

The present section sheds light on the recent methods of teaching widely used in modern and developed educational institutions and the possibility of applying them in the Iraqi educational system. Mainly, three methods are presented as for English language teaching is concerned: the audio-visual method, the audiolingual method and the communicative method. 


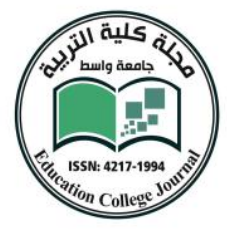

\section{2-1-1 The Audio-visual Method (Structural Global Method)}

So as to facilitate the acquisition of foreign languages, foresights of structural linguistics were applied to language teaching. This method renders learners to different transformation drills and structural patterns. It was developed in France in the 1950s and which

$a$ - uses recorded dialogues with film-strip picture sequences in order to present language items

$b$ - teaches speaking and listening just before reading and writing

$c$ - does not use the mother tongue language in the classroom

$d$ - uses drills to teach basic vocabulary and grammar.

However, this method is based on the belief that:

$a$ - translation should be avoided if new language items are taught in situations

$b$ - language is mainly learned through communication

$c$ - choice of items for teaching can be based on a careful analysis of the language being taught.

(Richards and Schmidt, 2002: 40; Berns, 2010: 417)

\section{2-1-2 The Audio-lingual Method}

Being partially based on structural linguistics and partially on behaviorism, audio-lingual method is based on the ideas that (a) each language has its own distinctive structure and rule system (b) speaking and listening are the most language skills (c) any language is learned through forming habits (Richards and Schmidt, 2002:39). By means of the Stimulus-Response Reinforcement model, Audio-lingual methodology, owes its existence to the behaviourist models of learning. It tries through a continuous process of positive reinforcement, to engender good habits in language learners. A distinct procedure of the audiolingualism is that of "PPP" (Presentation, Practice and production). In this procedure, the teacher in a presentation introduces a situation which contextualizes the language to be taught. Presentation focuses on a particular point of grammar, or the realization of a function, usually presented plainly in a context. This stage is supposed to develop an understanding of the language point in the learner. The student practices the language using accurate reproduction techniques such as individual repetition, choral repetition and cue-response drills. Later in a 


\section{العــــــدد السادس والعشرون}

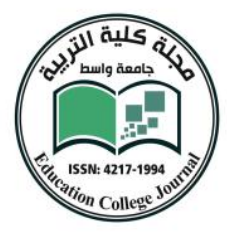

production procedure, the students, using the new language, make sentences of their own. PPP as a learner centered framework faced a lot of criticism, for it offers undiluted diet of the dry meaningless PPP-structured lessons. However, what is taught is not necessarily what is learned. Though PPP lessons are usually supplemented with skills lessons, most students, taught mainly through conventional approaches such as PPP, leave school unable to communicate effectively in English. Apart from highly talented and motivated students, most learners who work within a structure-based approach fail to attain a usable level of proficiency and fluency in the second language even after years of instruction (Skehan,1996: 18; Harmer, 2001, 79-82; Edwards and Willis, 2005: 5).

The tradition of language teaching at schools which follows the structure of a textbook and a routine sequence of presentation, practice, and production "often CLASHES with less controlled, learning-centered approaches to SL (and or FL) teaching and learning, such as the task-based approach" (Ellis, 2003; Berns, 2010: 364). However, PPP is considered, in Europe, as well as other countries like Brazil, as "well established and difficult to shake", for it is the only established approach to second language teaching (Edwards and Willis, 2005: 14).

\section{2-1-3 The Communicative Method}

As Harmer puts it (2001: 84-5) Communicative Language Teaching (CLT) is the name given to a set of beliefs which included not only a re-examination of what aspects of language to teach, but also a shift in emphasis in how to teach. The communicative approach, focusing on content rather than form, stresses the significance of language function rather than it focuses solely on grammar and vocabulary. A guide principle was to train students to use language forms properly in a variety of contexts and for a variety of purposes. What vitally important for a student's development of knowledge and skill were plentiful exposure to language in use and plenty of opportunities to use it are. Typically, activities in CLT involve students in real or sensible communication, where the accuracy of the language they use being less important than the successful achievement of the communicative task they perform. Replicating real language communication, the following principles are supposed to happen in this approach: 


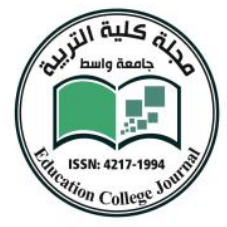

1- They need to have a purpose for communicating.

2- They need to have a desire to communicate something.

3- They have to be focused on the content of what they are saying or writing rather than a focus on a particular language form.

4- They should use a variety of language rather than just one language structure.

5- The teacher may not intervene to stop language activity, and

6- The materials a student relies on will not dictate what specific language forms the students use either.

Richards and Schmidt (2002: 90) say that CLT has led to a reexamination of language teaching syllabuses, goals, materials, and classroom activities and has had a main impact on changes in language teaching world wide. Some of its principles have been integrated into other communicative approaches, such as Task-Based Language Teaching, Content-Based Instruction, and Cooperative Language Learning.

\section{2-1-4 Task-Based Language Teaching (TBLT)}

Students are just as likely to learn language, as popularized by Prabhu 1987, if they are thinking about non-linguistic problems as when they concentrate on particular language forms, and they are presented with a task they have to perform or a problem they have to solve (Harmer, 2001: 86). As Edwards and Willis (2005: 18-9) put it, a language learning task is an activity, having a non-linguistic purpose or goal with a clear outcome and uses any or all of the four language skills in its accomplishment by conveying meaning in a way that reflects real- world language use.

Harmer (2001: 87) states thee steps for TBLT: "a pre-task, an introduction to topic and task; a task cycle, a task planning report; and language focus pertaining analysis practice". In a pre-task the teacher is supposed to explore the topic with the class and highlight useful words and phrases, and help students to understand the task instructions. During the task cycle, the students should perform the task in pairs or small groups while the teacher monitors from a distance. The students after that plan how they will tell the rest of the class what they did and how it went, and then they report on the task either orally or in writing, and $\backslash$ or compare notes on what has come about. In the focus language stage the students scan and discuss 
specific features of any listening or reading text which they have looked at for the task andlor the teacher may carry out some form of practice of specific language features which the task has provoked. The students are supposed to comprehend, manipulate and interact with the task.

Feez (1998: 17 cited in Richards and Rodgers, 2001: 224.) summarizes the basic assumptions of the Task-based Language Teaching (TBLT) in the following:

1- The focus of instruction is on process rather than product.

2- Basic elements are purposeful activities and tasks that emphasize communication and meaning.

3- Learners can learn language by interacting purposefully and communicatively while engaged in meaningful activities and tasks.

4- Tasks and activities of a task-based syllabus can be sequenced according to difficulty.

a. Activities and tasks can be either those that have a pedagogical purpose specific to the classroom, those that learners may need to achieve in real life;

5- The difficulty of a task relies on a range of factors including the complexity of the tasks, the previous experience of the learner, and the degree of support available.

With a focus on form in the context of meaning, as essential for efficient learning and effective communication, TBLT is gathering support from SLA research. In particular, Long and Robinson (1998 cited in Edwards and Willis, 2005: 16-7) stress the significance of focus on form for L2 learning by attracting students' attention to linguistic elements, as they arise in a meaningful classroom context, and not as discrete items presented to the learner. Therefore, drawing learners' attention to the formal properties of the L2 is also significant for language learning, but only if it is done while maintaining emphasis on meaning, fluency and communication. This assumption constitutes one of the basic premises of taskbased language teaching.

Mainly, five types of task are suggested: jigsaw tasks, information gaps, problem-solving, decision-making, opinion exchange. Pica et al. 1993 provide some definitions of the different task types: 

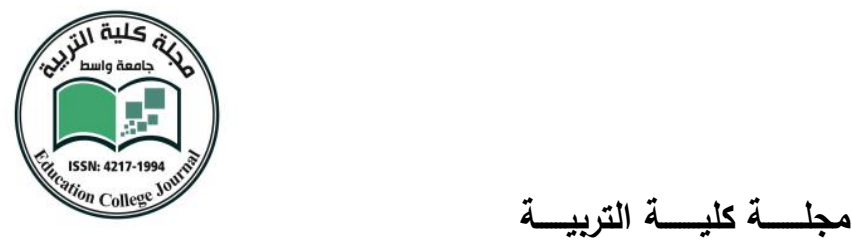

1- Jigsaw tasks: they involve learners who combine different pieces of information to form a whole (such that, three individuals or groups to have different parts of a story and have to piece the story together).

2- Information-gap tasks: One student or group of students may have one set of information and another student or group can have a complementary set of information. They should negotiate and discover what the other party's information is in order to complete an activity.

3- Problem-solving tasks: Students should be given a problem and a set of information. They have to arrive at a solution to the problem.

4- Opinion exchange: In pairs, students discuss ideas, give their opinions and say if they have one or have used one. Students exchange ideas to find out if they have made the same predictions. If they have made different predictions, the teacher asks students to justify their opinions.

5- Decision making. Students discuss in pairs or groups the choice between two or more matters of specific situation, giving reasons for their choice.

(Edwards and Willis, 2005: 19, 247)

\section{2-1-5 Cooperative Language Learning (Cooperative Interaction)}

As a team, students work together to complete a learning unit, such as a laboratory experiment. Cooperative learning activities are regularly used in Communicative Language Teaching. The use of Cooperative Learning principles in language teaching is recognized as Cooperative Language Learning (Richards and Schmidt, 2002: 124). The exchange of information can give learners the opportunity to receive feedback on the level of their comprehension in the L2. This can result in negotiated modification of conversation which renders the subsequent interaction more understandable, that is to say, it becomes comprehensible input (Edwards and Willis, 2005: 21).

Gillies et al (2008:1) state that peer-mediated learning is well recognized as a pedagogical practice that endorses learning, higher level thinking, and prosocial behavior in students from pre-school to college. For students to work together, they can have many opportunities to learn and develop a greater understanding of others with diverse interpersonal, social, adjustment, and learning needs. "The focus has moved to the role of teachers' discourse during cooperative learning and its affect on the quality of group discussions and the learning achieved and meta-analytic 
studies that have examined collections of studies to gauge the extent of the effects of cooperative versus other teaching-learning configurations".

Despite the well-documented benefits of cooperative learning, implementing this pedagogical practice in classrooms, or indeed any of the structured peermediation programs, is a challenge that many teachers find difficult to accomplish. Difficulties may occur because teachers often do not have a clear understanding about how to establish effective cooperative groups, the research and theoretical perspectives that have informed this approach, and how they can translate this information into practical classrooms applications (Gillies et al, 2008: 2).

\section{2-1-6 Content-Based Instruction}

Content-based instruction, the incorporation of materials drawn from content areas such as social sciences, literature, the arts, and so forth into language instruction, seeks to realign foreign language instruction with the humanistic and intellectual missions of the academic curriculum. The focus in content-based instruction is something other than the language. The content, music, history, or literature, for example, is taught in the second language. Immersion programs at the elementary, secondary, or even university level, where the whole curriculum is taught in the second language, offer greatest possible exposure to language for a purpose. Adding to that, task-based curricula are designed to afford learners with the most opportunity to use language for a purpose (Bussmann, 1996: 244; Sandra, 2002: 12).

Content-based instruction is also known as the content-based language approach in ESL programs. The content-based ESL classes, designed for second language learners only, are taught by language educators whose main goal for students is English language development but whose secondary goal is preparing them for the mainstream, English-medium classroom. Teachers can develop the students' English language proficiency by incorporating information selected from subject areas that students are likely to study, or from courses the students could have missed if they were new to the school system. Content-based instruction is often accomplished through interdisciplinary or thematic units, such as a rain forest ecology unit, and lessons could include objectives drawn from life history, sciences, or mathematics as well as ESL. Throughout the different content areas, course syllabus and topics are usually covered. The content-based language 


\section{العــــــدد السادس والعشرون}

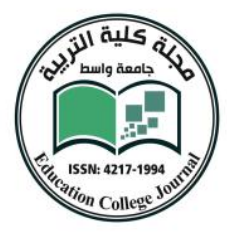

approach constructs a forum for subject area knowledge application, generation, and reinforcement by addressing key topics found in grade-level curricula. Students acquire subject-specific, academic vocabulary, background knowledge of multiple concepts, and practice in academic tasks and skills common to mainstream classes. The presented sophistication of the material varies according to the grade level and language proficiency of the students, but it is nonetheless relevant and meaningful to them because it is tied to school subjects. Attention to language development is dominant with focus on both function and form within the content themes (Berns, 2010: 272).

\section{2-2 Promoting Genre Awareness in EFL Classroom}

EFL students need explicit instruction in genre features, patterns and variations, so as to succeed professionally and academically. Genre is one of the most important and influential concepts in literacy education. Swales (1990: 58) defines Genre as "a class of communicative events, the members of which share some set of communicative purposes". It is also defined as "a term for grouping texts together, representing how writers typically use language to respond to recurring situations", for it is based on the idea that members of a community generally have little difficulty in recognizing similarities in the texts they use frequently and are able to draw on their repeated experiences with such texts to read, understand and perhaps write them relatively easily. In a genre based curriculum, all text depends on the context in which they are used. Genre proponents should aim to draw together language, content and the context of the discourse interpretation and production. The major belief "is that we don't just write, we write something to achieve some purpose (Paltridge, 2001:2; Hyland, 2003:18; 2008: 543).

By exploring different genre types, such as description, narrative and recount, in relation to their purposes, the discourse organization, their context, and lexico-grammatical patterns, students can be encouraged to notice how language works. Thus, using genre is a guideline principle for EFL syllabus design (Bax, 2006; Millar, 2011 Cited in English Teaching Forum 49 (3, 10)).

In their classes, teachers should incorporate a range of genre awareness activities which ask students to notice how language works in relation to the context. Genre awareness aims to assist students in developing the rhetorical 


\section{العــــــدد السادس والعشرون}

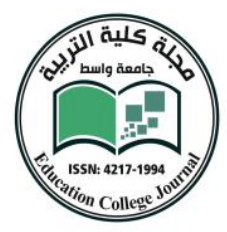

flexibility necessary for adapting their socio-cognitive genre knowledge to everevolving contexts, being the ability to select and use an appropriate genre based on a number of factors, including the purpose of communication, the context and the people involved. This approach, also known as consciousness-raising, assists students both to create text and reflect on writing by helping them to focus on how a text works as discourse rather than on its content (Hyland, 2003:87; Johns, 2008: 238).

\section{2-3 Some Concerns about English Language Teaching \Learning}

English language teachingllearning puts up with the long isolation, neglect and retreat from the modern methodology at the educational institution in Iraq, especially for the last two decades. Though there has sprung a rising to coincide the world accelerated evolvement, still the educational institution hasn't been up to the educational needs, especially in developing the higher institutions of education; on the other hand, curriculums of English are unstable, owing to political and financial evaluations rather than educational ones. The following are clear cut problems that may be considered as obstacles facing the educational progressing in Iraq.

\section{2-3-1 The Wash-back Effect on Classroom Teaching}

Public examinations, in most societies, their teaching and learning, their relationship to the curriculum, and their effect on individual opportunities in life are of vital importance. The current widespread use of examination scores for various educational and social purposes has made what is called "wash-back", which is a distinctive educational phenomenon. According to Messick (1996, 241), wash-back," as a concept prominent in applied linguistics, refers to the extent to which the introduction and the use of a test influences language teachers and learners to do things they would not otherwise do that promote or inhibit language learning" . There is evidence to suggest that examinations produce wash-back effects on teaching and learning. In Iraq for example, most of the students, as well as the teachers incline to use sketches based mainly on specific models of public examinations and almost skip many classroom activities and techniques that raise the students' educational level. In other word, a focus is made only on what is expected to come in the exam, rather than accomplishing the objectives of the syllabus. 
The immediate changes in public examinations can be reflected in an integrated reading, listening, and writing exam, and require students to perform simulated "real life" tasks, together with an increase in the weighting of the oral component. The new oral component can reflect a dramatic change from the previous guided conversation and reading aloud to new task-based group discussion and role-play. Both components require that students should be taking an active role, participating fully in language interaction, and carrying out tasks using different integrated language skills. Many major innovations of recent years have been designed with the probability that examination changes can help classroom teachers to promote a better balance between teaching and skill-building on the one hand and examination preparation on the other. Still, there is an urgent need to find out whether and to what extent the change in the public examination to a more integrated and task-based assessment format resulted in change in English language classroom teaching (Sandra, 2002:92-3).

\section{2-3-2 Oversimplification in Presenting Rules of Grammar}

Pedagogic rules of grammar can inform much language teaching, but if they are applied carelessly, they can sometimes lead to considerable over-simplification. Nonetheless, proliferating rules without end make the learning more difficult (Harmer, 2001: 15-6). Oversimplification is almost the consequence of the noncongeniality between the curriculum level and the students' educational background. With accumulative difficulties of learning, almost, teachers in Iraq try to facilitate learning through oversimplifying and overgeneralizing pedagogic rules of grammar, as in figure $1 \mathrm{~A}$ which in turn results in complicating the matter especially when the students face patterns of language flouting the oversimplified rules, e.g. some teachers instruct students that whenever they see "ch", as stated in some helping sketches, it is pronounced $/ \mathrm{t} \mathrm{f} /$, but the flouting occurs when students face words like "machine or mechanic". 


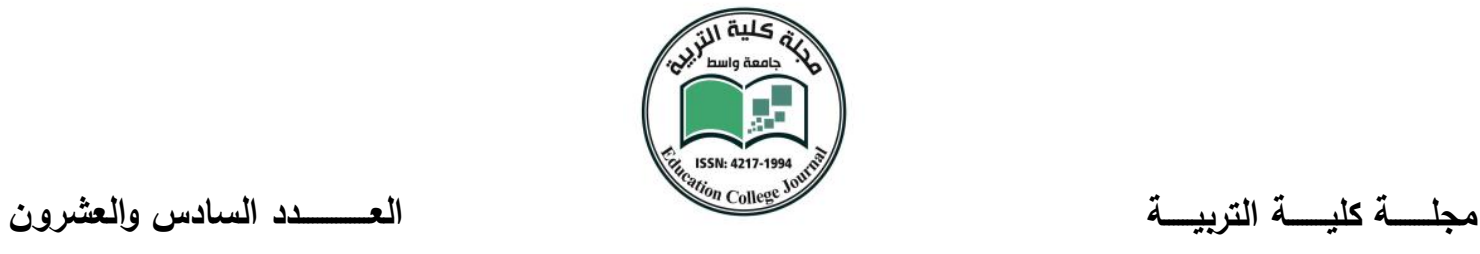

2-3-3 Problems of Teaching with a New Methodology

Teaching with a new method can take different concerns:

1- As Students' previous learning experiences may have predisposed them to one particular methodological style that makes them uncomfortable with unfamiliar teaching patterns, a teaching method can be critical to students. Furthermore, they might be uncongenial to certain teaching and learning activities that replicate the teaching they received earlier in their educational careers.

2- Students almost have experienced criticism or failure at school which makes them under-confident and anxious about learning a language.

2001: 40)

(Harmer,

3- Teachers themselves may not be well aware of the new method of teaching that a new curriculum tackles; hence, they could present the new one with the applications of another they have handled before. Teachers of English, referring to those in Iraq, have not got a precise instruction about the modern methodology of teaching. It is until 2013 and the college students of English study an old-fashioned book of methodology by prof. Khalil AlHammash, authorized more than 40 years ago, and still this is the curriculum of methodology of many institutions of teaching English like the Open College in Wasit. This curriculum though one of the best at that time, it lacks lots of the articulatory procedures and programs used in modern methodologies and curriculums, particularly those of the communicative approach. 


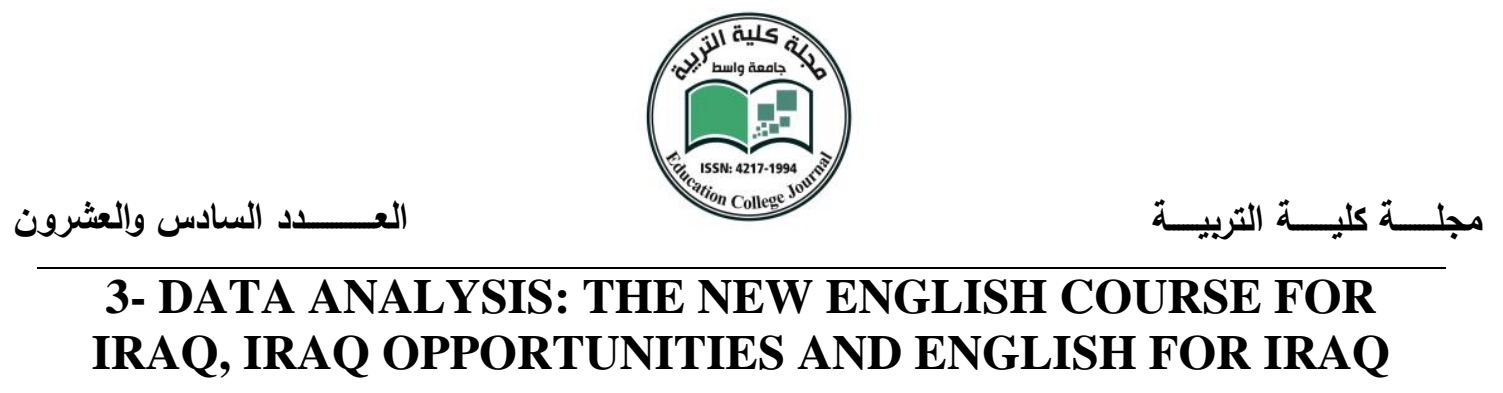

The present chapter is concerned with an analysis of the methodology and techniques used in the presentation of the syllabuses (used in preparatory classes) of teaching English language in Iraq, especially in the latest years. The analytical procedures shed light on the methodology used in the syllabus design, taking into consideration the four skills (writing, reading, speaking and listening activities), adding to that the prominent obstacles that face the teacher and the learner of English in achieving the educational aims, and an exposure to the technical aspects of the syllabuses. The syllabuses to be concerned are "The New English Course for Iraq", English for Iraq" and "Iraq Opportunities". So, the present chapter analyses each syllabus, in relation to the methodology used in teaching the syllabus, the presentation of dialogues and context, genre exploitation, vocabulary, language and rules of grammar, patterns of language as well as the four skills of teaching.

\section{3-1 The New English Course for Iraq (NECI) (Book 8)}

NECI consist of a student's book and a story. The system of teaching as far as this syllabus is concerned was limited to the reading and writing skills, though with little focus on writing, and no attention was paid for listening or speaking activities. A syllabus, based on a classical structural method with lesson procedures of explanation, recognition and creation, was the prevailing over teaching English language in Iraq.

Reading comprehension is composed of a reading passage with some comprehension questions or drills about it. The passages as for the reading comprehension are not based on a communicative method. Students are not stimulated to express their opinions or talk about the topic of the reading passage, being presented with an audio-lingual method of teaching.

Dialogue activities do not exceed a conversation between two or more interlocutors and not a matter of communication among students. However, the dialogues exhibit grammatical or lexical patterns, showing an audio-visual method, though recordings of dialogues were not available. Dialogues almost have no specific topic and decontextualized. They were entirely ignored as a class activity as they had no role in the questions of the final examination, and that is clear from 


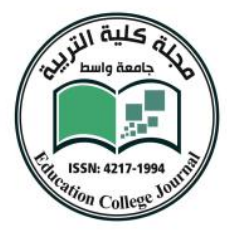

the helping sketches which most of the students depend on at their study; more than $90 \%$ of the sixth preparatory students depend on those sketches which almost focus only on what was expected to come in the exam.

Literary reader (The Tale of the Merchant of Venice) has wide range of reading comprehension, written compositions, and speaking activities. Though the NECI is mainly based on an audio-lingual approach of teaching, the literary reader has a precise role for a communicative mode to manipulate the text, especially with a content based instruction. Literary reader was not exploited due to the aims of the syllabus methodology, since the majority of the teachers, because of the shortage of time, do not work on a communicative method; rather, they depend on sketches that contain the more frequent questions of the bachelor examinations with their suggested answers, that is in addition to written compositions that are also of the more frequent in the final exams. This is evidenced from the sketches which are used by most students and the majority of teachers.

(Note: the above information is based on the researcher's observation, the opinions of expert teachers as well as the amount of sales for these sketches and the students' proceeding to buy them).

Teacher's main focus in teaching the NECI was directed towards teaching (oversimplified) rules of grammar which was, for the teachers, the best way to make the students speak properly, and the shortest to make them pass the exam. The continuous failure of the students makes the teachers conduct a methodology which even out of range of the determined syllabus. Grammatical structures are presented in a classical mode where rules of grammar to be presented first, with a full translation, followed by solved drills, where students try to memorize, not comprehend, grammatical patterns.

Listening activities has no position in teaching the NECI, simply because there were no audios available nor did the syllabus tackle listening activities except with phonetic transcripts, for which the audios were not available. Speaking activities can take their form only if the syllabus is based on communicative model with clear genre and plain topic. Though this was applicable with literary reader, speaking was not activated for the same reasons mentioned above. The NECI includes the translation of the new words after each reading passage of literary reader section. This can facilitate the difficulties that may face the student in using 
a dictionary. Vocabulary study occurs, after reading comprehension, to integrate student's awareness of vocabulary with his comprehension of what he reads. As the NECI was authored, by Professor Khalil Al-Hammash, at the seventies and eighties of the last century, little attention was paid to collocation patterns and idiomatic expressions, where they were paid more attention at later studies. However, vocabulary was presented at a methodology that mixes between structural and audio visual methods.

\section{3-1-1 The Prevailing of Helping Sketches}

A phenomenon that prevailed the NECI teaching is the use of informal sketches, containing oversimplified rules of grammar and answers to some drills in the text book. The following concerns can be presented about those sketches:

1- They are presented as a replacing to the NECI syllabus.

2- They prevailed to teaching the NECI; scarcely can you find a student without a sketch or more in his study to NECI, Book 8).

3- Sometimes they exceed the ranges of the syllabus, and could reach a triple of the syllabus, or it may stint and skip many activities and lessons in the text book. The following are some examples of that: 


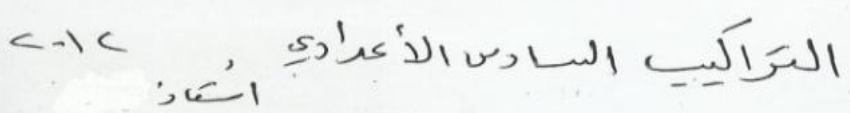

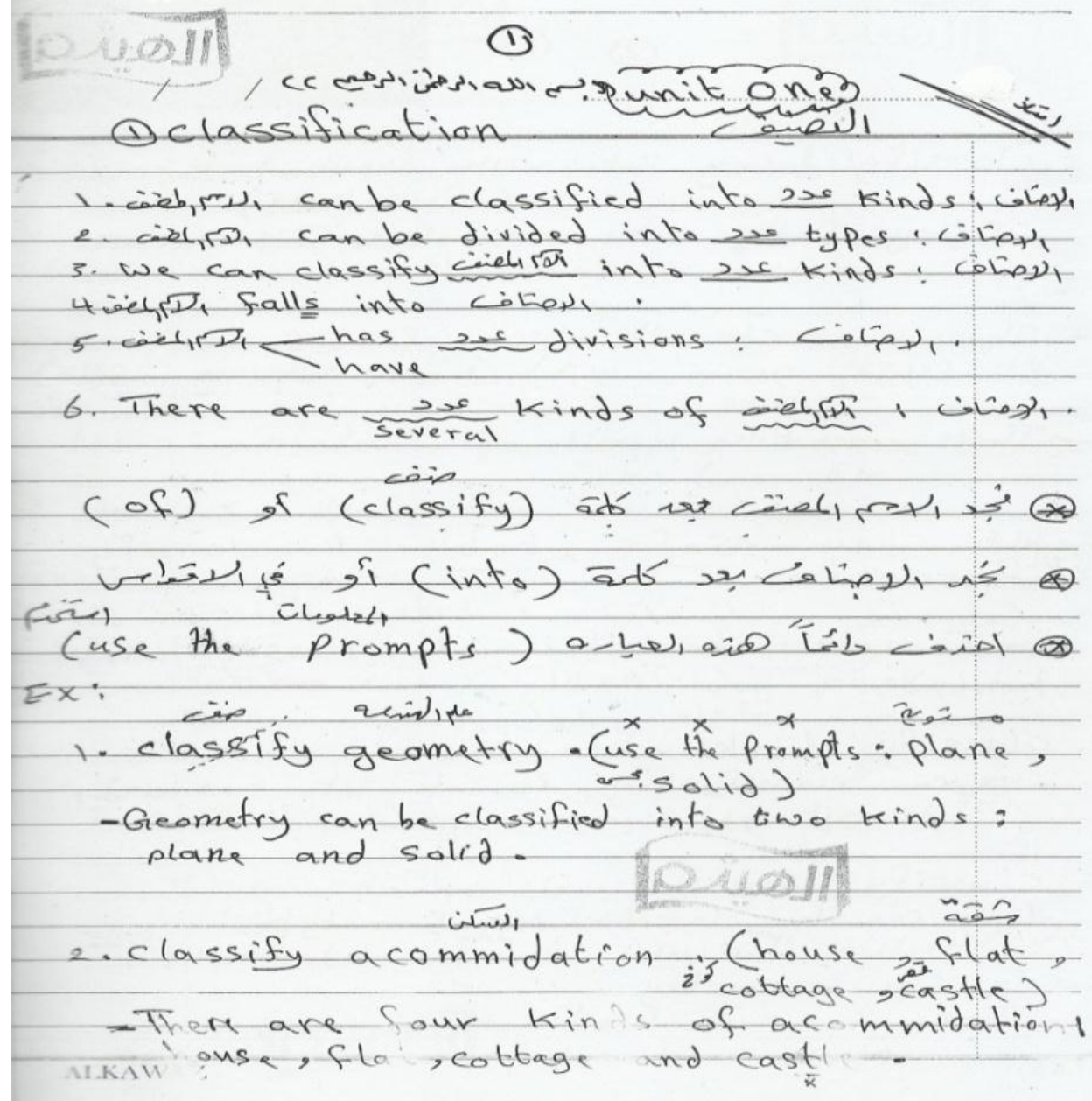

Figure 1: A- a sample of helping sketches with oversimplified rules of grammar 

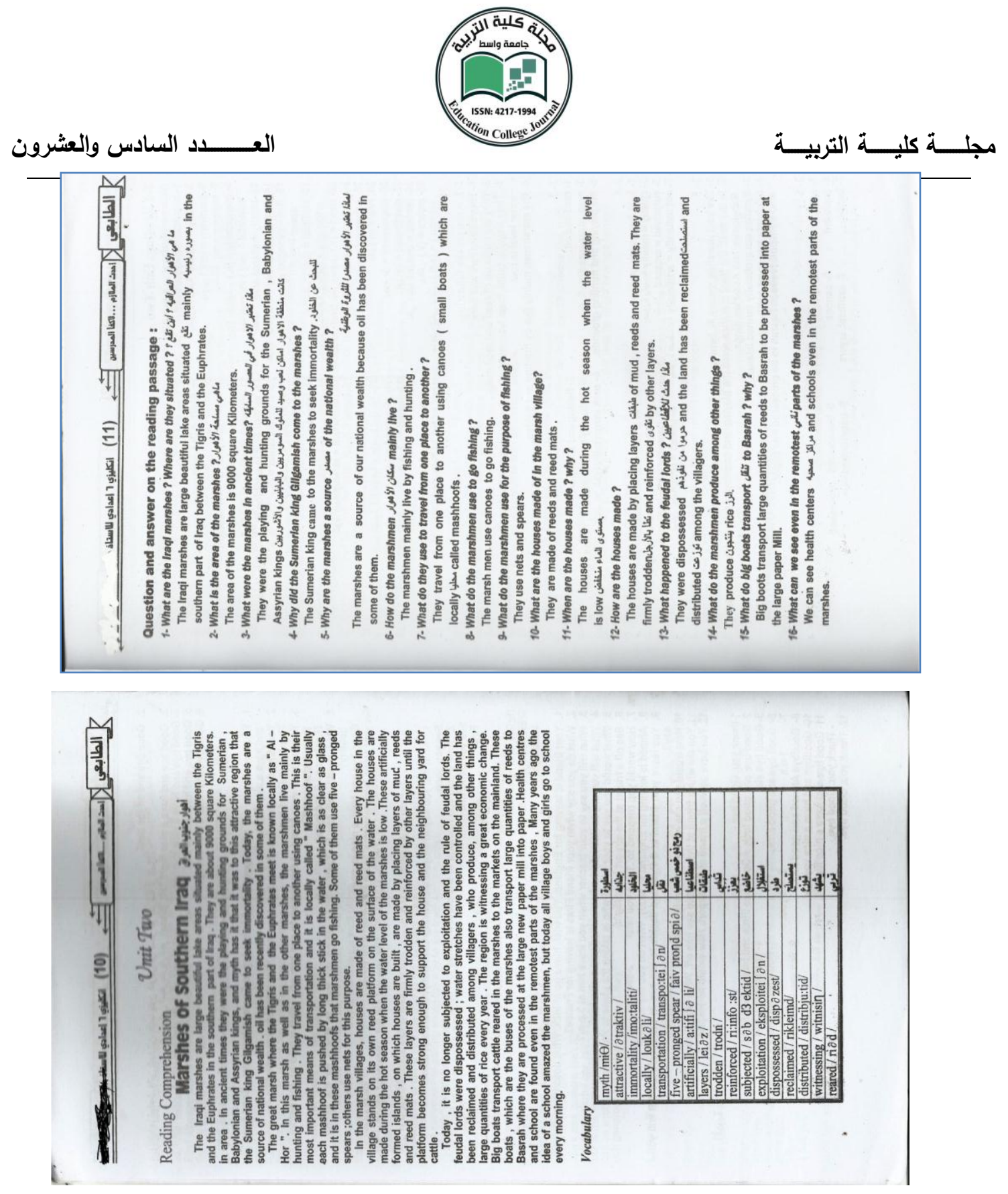

Figure 1: B-A sample of helping sketches replicating a reading comprehension of NEFI, Book. 8, p.16-7, with suggested questions and answers. 


\section{العــــــدد السادس والعشرون}

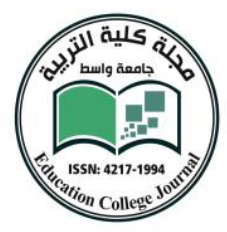

Such sketches simply abolished the aims of the syllabus, stimulating to memorization of the drills and oversimplified rules about them. They also abolished homework activities since students can have the exercises already answered. This in return attenuated the teacher's role in the class and student's creative aspect. However, this mode of teaching prevailed for decades with no reaction or manipulation toward such unprogrammed methodology. Teaching NECI under these conditions is evidenced to fail the educational progression of the students. According to the researcher's statistical account for the students who participated in the bachelor exam of English for the year-study 2010- 2011 in Wasit province, only $\underline{\mathbf{1 1 2 3}}$ of scientific study students succeeded from $\underline{\mathbf{3 3 8 4}}$, which means that about $67 \%$ of the students failed in the final exam. On the other hand, only $\underline{\mathbf{7 7 3}}$ of literary study students succeeded from $\underline{\mathbf{3 6 7 0}}$, which means that $\mathbf{7 9} \%$ of the students failed in the exam. Adding to that, about $60 \%$ of those who succeeded got less than $\mathbf{6 0}$ degree in the final exam of English; which case exhibits a decline in the students' proficiency and fluency levels in English language. Without a quality control over such phenomena, the syllabus textbook will be only a secondary and optional choice for the students to learn. This phenomenon needs an urgent solution and cultivation for depending syllabus items by enhancing confidence on it, whether through workshops or positive backwash.

\section{3-2 English for Iraq}

Being composed of a student's book and an activity book, $5^{\text {th }}$ and $6^{\text {th }}$ preparatory are to be tackled; teachers' book presents the following points about the syllabus to be considered:

a- It is a student centered curriculum (" students to ...... Become more independent learners" TB. p. 2).

b- As a topic-based course that follows a clear functional and grammatical syllabus, an emphasis of topics is on life outside school and life after school.

c- It is suggested, because "that lessons can only provide a framework within which language can develop", the students need to study independently or take additional courses of study or travel to English speaking countries (TB. p. 2).

d- The syllabus applies a communicative approach to teaching and learning. 


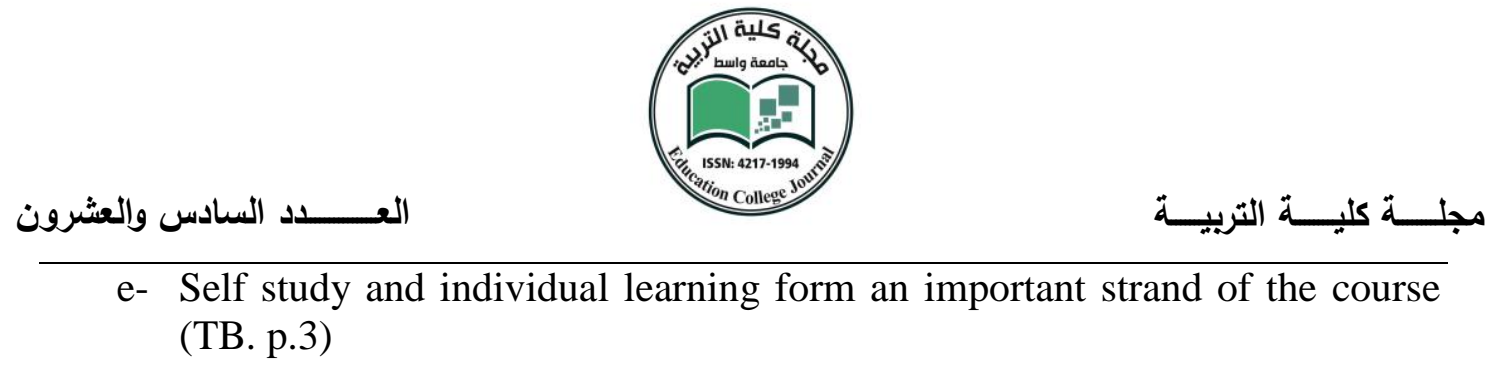

English for Iraq (EFI) is a new experience in the Iraqi educational system. Moving from the student's book to an audio track to the activity book burdens the teacher more efforts to the shortage of lesson time, adding to that the obstacles when moving from one activity to another between the books and audio instruments. In other words, much of the lesson time is dispersed with such movements. It is noticeable that EFI imposes many procedures, fusing more than one skill at a single lesson activity, which in turn can disperse student's attention and attenuate the teacher's manipulation over the variation in the lesson. The EFI contains a wide range of reading comprehension which includes reading passages of interesting topics with rich language. But, what is critical in these is that they are not based on a communicative method of teaching since they are presented in a way that not only disallows the students to communicate but also does not stimulate them to read the text. For example, in the following lesson in figure 2, cited from EFI, $5^{\text {th }}$ preparatory, $\mathrm{SB}$, p. 76 , the students are supposed to match the paragraphs with the headlines, though they can make the matching just by comparing the headlines with the pictures beside each paragraph. However, reading passages are presented in a PPP method, while communication has no role in such presentation. As reading comprehension coincides the widest range of communication, the lesson requires students to show their opinions, give advice, agree or disagree, etc, toward a specific task or topic raised even before reading a text. Comprehension and thinking work together when there is a motivation brainstorming students for that, resulting in a communicative method. 

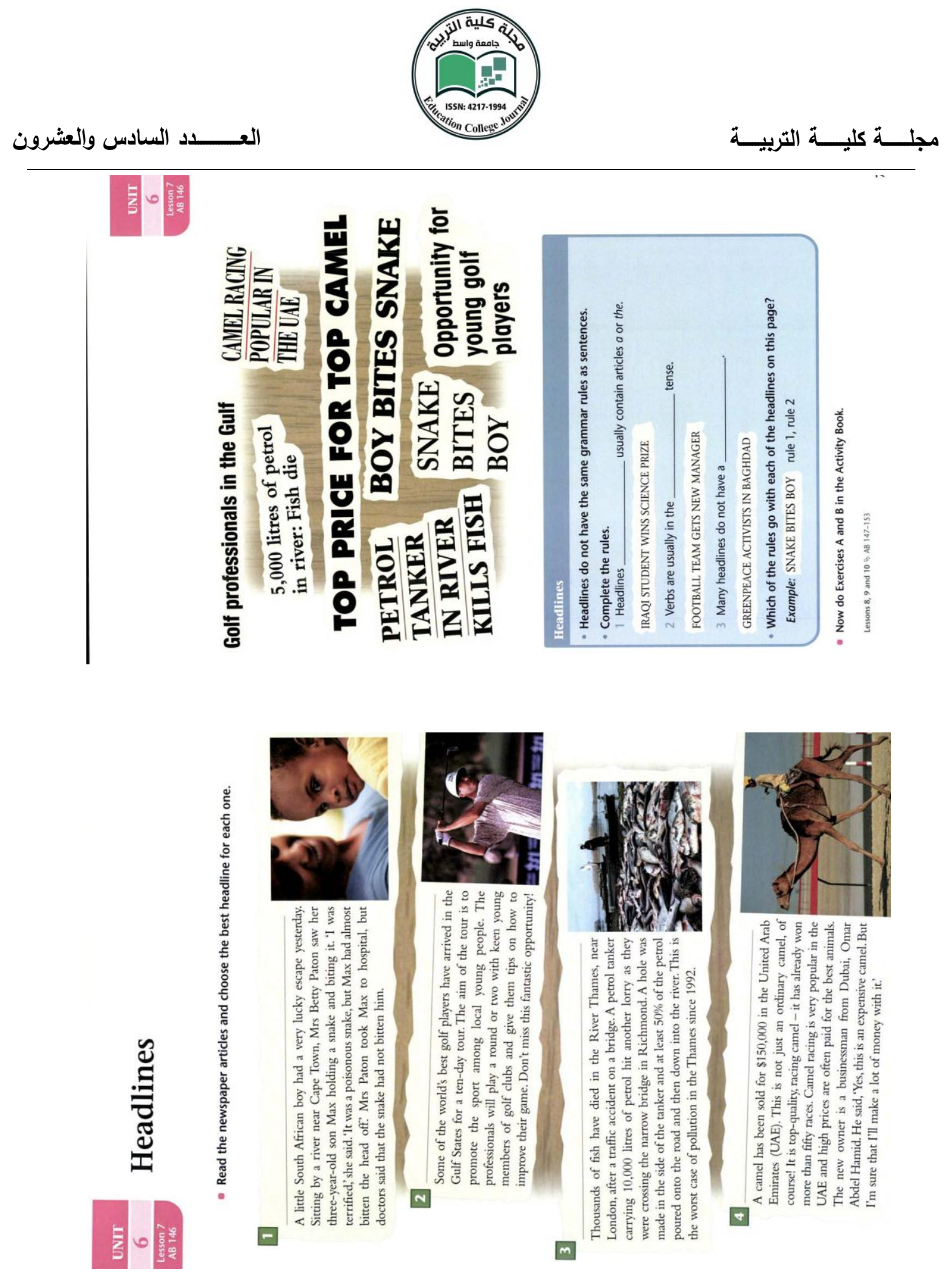

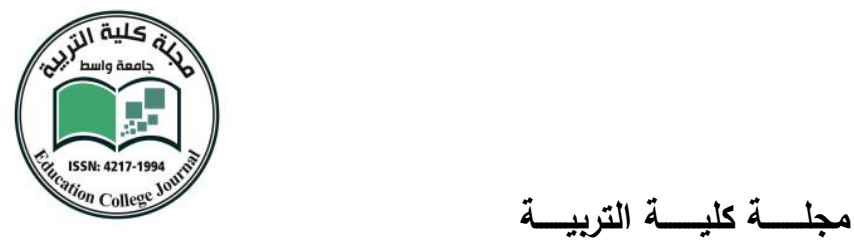

Figure 2: A sample of reading comprehension, EFI Book 7. SB. P. 67-8

Hence, the curriculum on which this book is based does not owe to a communicative approach, as claimed, but restrictively to a PPP one. On the other hand, the lesson is not a task based one since it attenuates the role of the text because it should direct students' attention to the text, by moving the pictures for example, andlor giving students questions stimulating them to talk and express their impressions before and after reading the text, such as: How do you feel about snakes? Have you ever played the golf? Contamination of our environment! Would you like to have a camel?, etc. The reading comprehension sample can be exploited at better procedures, in addition to those mentioned above. It is possible to work on questions exciting students for the content of the passages, build structural notes or lexical patterning, or relating each passage to a specific topic.

EFI does not focus on genre as a sort of syllabus building; a focus is made on patterns and topics that almost contain sentences that are related in form rather than in content. This resulted in unnecessary tautology which almost overlaps the syllabus formulation. Figures 3 and 4 are clear examples from $5^{\text {th }}$ and $6^{\text {th }}$ preparatory; in Figure 3, repetition of the same structural pattern with auxiliary verb " $d o$ " is not related to a topic nor does it pertain to any sort of task or content based teaching; in figure 4, a tautology of the lexical pattern "she asked her-", and a focus on repetition is clear cut. 


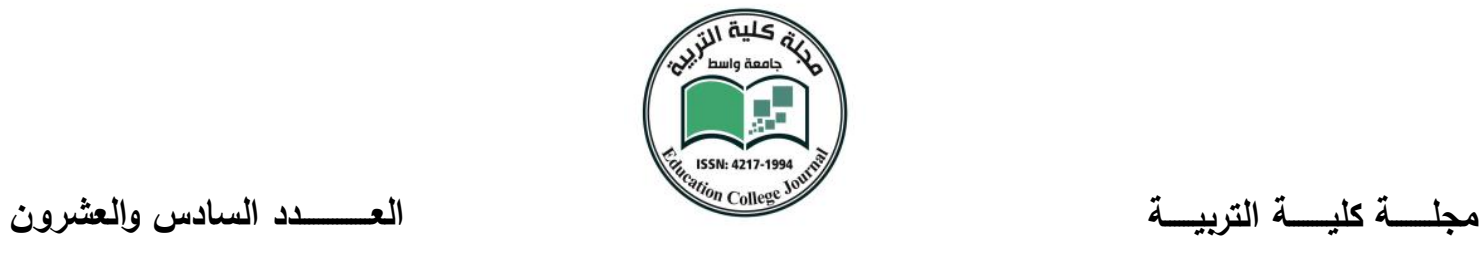

C Complete the questions with much or many.

1 How food do we need to bring to the picnic?

2 How apples do we need?

3 How meals do you eat a day?

4 How sleep did you get last night?

5 How exercise does he take a week?

6 How hours' sleep did you get the night before?

7 How time do you spend on your homework?

8 How times a week do you wash your hair?

Figure 3: A sample drill of EFI, Fifth preparatory. SB. p. 75)

Figure 4: A sample drill, EFI, $6^{\text {th }}$ preparatory, AB. P. 13

\section{Read the interview. Are these sentences True or False?}

1 Eman asked Widad where she sold her paintings.

2 She asked her which colours she liked best.

3 She asked her if the prizes were important to her.

4 She asked her how much time she spent working.

5 She asked her whether she had taught anyone to paint.

6 She asked her where she studied.

7 She asked her what her favourite subject was.

8 She asked her where she lived.

9 She asked her whether she preferred painting or other arts.

10 She asked her how much money she had made from her paintings.

11 She asked her why she had stopped painting.

12 She asked her what she was going to do next. 
However, it is noticeable that the syllabus focuses on form rather than content, without paying attention towards genre awareness, communication, nor relating the reading topics to the student's own life and experiences.

As for listening, some of the listening activities of guided conversations are just repetition to the reading texts. Fusing listening with reading disperses and drifts student's focus towards reading, particularly with the difficulty of the audios accents, as observed by the researcher. The students almost complain they always can't perceive the audios, and that is because the speakers in the tracks exaggerate in using assimilation, elision and neutralization which are so problematic to nonnative speakers, the students as well as their teachers. As in figure 5, listening to the audio is just to make students hear what they are going to read, a case which does not stimulate students for listening to the audios, with no brainstorming ideas or communicative method.

\section{- 8 (1) Listen and read.}

\section{Fareed: Why are you writing to your mother? You live in the same house. And you see her every day.}

\section{Alex: I know, but it's Mother's Day tomorrow.}

Fareed: Tell me more about it.

Alex: Well, it's a day in the spring when you say thank you to your mother for everything. Most people give their mother a card and a present.

Figure 5: A sample of guided conversation, EFI, $5^{\text {th }}$ preparatory, SB. P.6.

\section{3-3 Iraq Opportunities (IO)}

Being composed of a student's book and an activity book, Iraq Opportunities has been taught up to fourth preparatory, starting from the primary school, third class. As a communicative- task based- curriculum, it presents the activities tasks within three stages: a- preparation, b-performance and c-reflection. And as a content based curriculum, being composed of Cross-curricular themes, it incorporates materials drawn from content areas such as social sciences, literature, 


\section{العــــــدد السادس والعشرون}

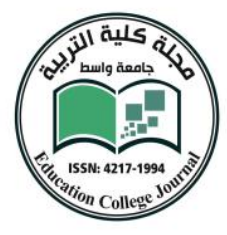

the arts, business, which case introduces students to a range of concepts and vocabulary pertaining these areas, and provides opportunities for students who plan to opt for any of these specialisms to extend their English language skills within the field.

Lesson planning includes staged presentation for grammatical structures, lexis and teaching skills, in relation to context. Seeing that the unites, the lessons and the tasks are topic based, and since students are writing for a purpose and not merely to get a mark from the teacher, a hierarchy of topics is indicated throughout the general formulation of the syllabus. What distinguishes this curriculum is that each topic starts with brainstorming ideas where students establish and perform their speaking tasks. IO depends authentic, rather than fabricated, task-based roleplay and group discussion. Literature spots and science topics are designed in a way that coincides specific genres so concomitant to students' other areas of study and presents information of general cultivation.

As compared to EFI, IO presents the lesson at a highly communicative, task and content based, and cooperative language learning methodology, relating topics with teaching skills, on the one hand, and with grammatical structures and lexis on the other. IO stresses language function and reflects lessons topics to student's own life, inclinations and thoughts.

Much flexibility is made between the student's book and the activity book, since teachers can assign the consecution of the activity book at a freer mode: a teacher can assign it after a topic accomplishment or chapter accomplishment; it is possible to do the drills at class or assign it as homework; the teacher can discuss the drill at class time or take the activity books to check the answers out the class time, due to the time available for the teacher. On the other hand, the lessons are designed in a way where breakage between classes does not confuse the connectivity, i.e. we can start where we finished. As a comparison, a reading passage presentation in EFI ( $5^{\text {th }}$ preparatory, SB. p. 44$)$ is "Read the Article quickly and answer the questions on Activity Book page 80", while a presentation of a passage in IO $4^{\text {th }}$ preparatory, SB, p. 16 , is "Before you read a text, look at the photos and drawings with it", exhibiting a big difference in the style of stimulating the students for a communicative lesson. An example of a task based drill is that of figure 6 , where a riddle is presented to minimize the routine of lesson activities. 


\section{Who am I?}

No stomach have I, but eat all things,

The tree, the flower, the bird that sings.

I bite at iron, ruin 1 towns,

I throw the highest mountain down.

And at the end, when all is done,

I'll pinch2 the stars out, one by one.

\section{ANALYSIS - PERSONIFICATION}

1- Read the riddle 'Who am I?' Who or what do you think is speaking?

2- Why do you think the personification in the poem is effective? Give reasons for your answer.

3- Think of an object or an abstract idea and write a similar riddle about it, using personification.

Figure 6: a task based drill, IO, SB, p. 69.

The questions in the drill are presented in a way that stimulates the students to express their own ideas or what they "think". Relating the lesson topic to students' thinking enhance their comprehension and make learning easier for them.

An example of what is mentioned about the IO can also be propounded in figure 7, showing the integrity between the components of the syllabus at a lesson class. In figure 7, of IO, Fourth Preparatory, SB. p. 14-5, the topic "Eccentric" puts forward a picture telling a story that includes lots of things and ideas that attract the student's interests, giving him an impression of what is going to be tackled.

With a communicative mode, the lesson starts with stimulating steps for reading the text, asking students to talk about any eccentric person they know. This gives students a chance to express their own ideas and to try authentic, not fabricated, manipulation of language. Hence, a connection between context, reading and speaking, to be exploited for grammatical (present perfect) presentation is made for the build-up of the lesson. However the topic ends with 
listening and writing activities, all of which are task based and related to the topic of the lesson which successively is a sub-topic of the unit topic. This enables the students to gain an insight over the lesson course. At a wide range of the syllabus, the prominent formulation of the exercises in this book is that they are almost composed of a cohesive text, with patterns related to the main topic of the lesson. So, IO is based on a communicative, task based and content based, cooperative language learning curriculum. In figure 6 , for example the students are presented a riddle which they are supposed to think about and answer, showing a task based language learning. 

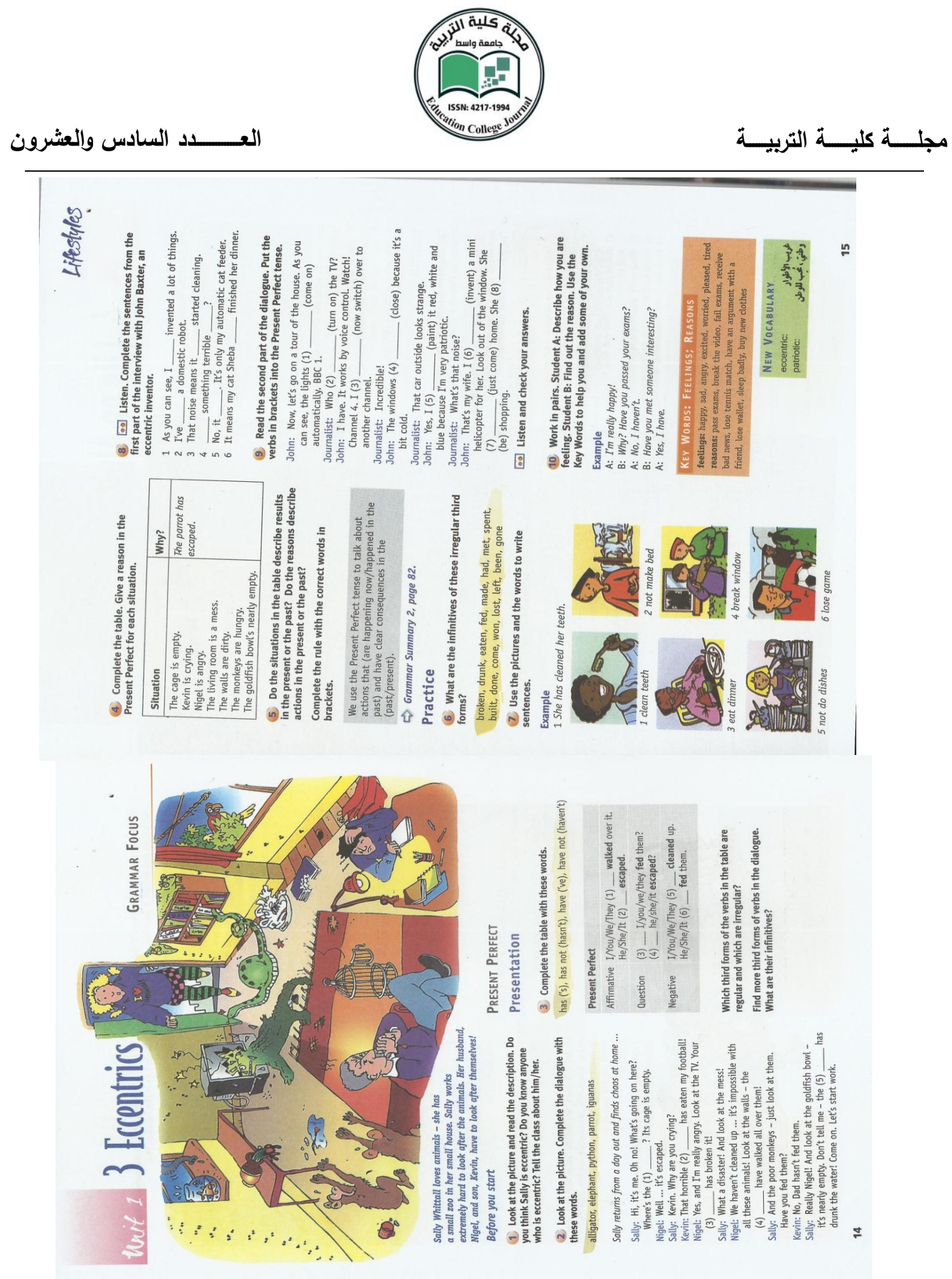

Figure 7 : A sample topic based lesson, 659 Fourth Preparatory. SB. p. 14. 


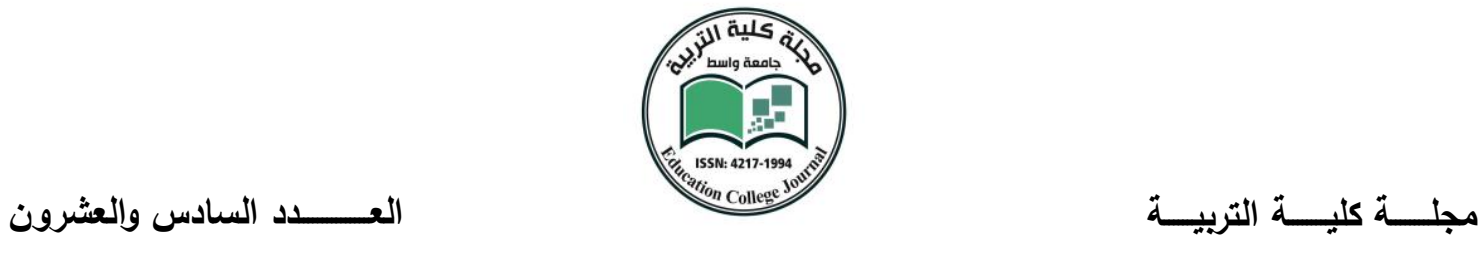

\section{3-4 Technical concerns}

\section{3-4-1 Lesson Planning and Preparation for a Communicative Lesson}

As for lesson planning, teachers who worked on teaching NECI suffered from the absence of the teacher's guide which provides the teacher with the consecutive steps to be followed in the class lesson at all stages, excluding from that some teachers who had the $6^{\text {th }}$ preparatory guide; scarcely can one find a teacher with a teaching guide for other stages. It is possible to say that less than $10 \%$ of teachers have a teacher's guide to teach the NECI. Hence, it was the teacher who draws the plan for the syllabus.

An extensive lesson planning is presented at the teacher's guide of EFI syllabus. The teacher is supposed to read two or more pages of details for a single lesson. Adding to that, it presents a lot of unnecessary information, such as the dialogues which are repeated in the student's book as well as the teacher's book. The teacher's guide of Iraq Opportunities is more concise and more precise since it gives the required information with fewer details, seeing that IO teacher's guide contains $\underline{103}$ pages while EFI teacher's guide contains $\underline{261}$ pages, taking into account that of IO includes the pages of SB within the guide pages.

Another concern about lesson planning is that the teachers are obliged to present a peer lesson plan. The supervising office induces the teachers to present a written lesson plan, including a weekly and year plan, though the syllabus design and teacher's guide present a clear cut planning and details. The teacher does not need to spend his time planning for the lesson while he has a precise lesson plan in the teacher's guide which he needs to check. However, lesson planning does not mean that the teacher formulate a plan of his own, but to follow the steps and details in the guide book.

\section{3-4-2 Paper Type and Spaces}

One of the problems of teaching EFI is that, though the papers are made of high quality, the light reflected on the paper causes a difficulty in reading the text in the book, and that is because the type of paper reflects light. This problem does not exist in the IO text. However, EFI contain a lot of blank pages and picture of exaggerated size. As for $5^{\text {th }}$ preparatory, SB, every unit starts with a blank page, taking 8 pages; all dialogues are rewritten at the end of the book, taking 44 pages; 
wordlist which can be replaced by a useful mini-dictionary, taking 39 pages. So, about $50 \%$ of the SB is just additional cost, indicating a non-economic book.

\section{4- CONCLUSIONS}

1- Teaching in Iraq is not in an urgent need to be developed with new methods more than a need for reforming in the educational system and finding solutions to the teaching obstacles, such as those of using helping sketches prepared by unprofessional teachers, students' diverge from the syllabus, abolishing homework activities, and presenting oversimplified rules of grammar to be considered as bases for learning language. Without a quality control over such phenomena, the syllabus textbook will be only a secondary and optional choice for the students to learn.

2- The more fabricated language teaching would be the less comprehension the students demonstrate towards learning. Genre exploitation in classroom approximates the lesson to authentic life situations, making teaching closer to students' comprehension.

3- The teachers do not need to write a lesson plan of their own, but to follow the planning in the teacher's guide.

4- The students (of preparatory classes) in general conduct a mode that may help them pass the exam rather than learning the English language. So, backwash learning mode has been conducted rather than language learning. A backwash effect resulting from the lack of coincidence between the syllabus and the questions presented in the final bachelor examinations prevailed the NECI learning; this can be avoided for the new curriculum by presenting the exams to be relatively compatible to the syllabus, so that the students, as well as the teachers, would retrieve confidence with the syllabus.

5- As compared to NECI and EFI, IO syllabus is more systematic, more communicative and more felicitous for both the teacher and the student.

6- Though "English for Iraq" (EFI) focuses on language interchange as turntaking conversations, still it is not communicative; that is because turn taking is a text of interlocutors interchange, while communication is a student-teacher or student-student interchange. The best way of presenting a dialogue is that of $\mathrm{IO}$, since it combines context, task, grammar and language within student's interchange, showing integrity among the 


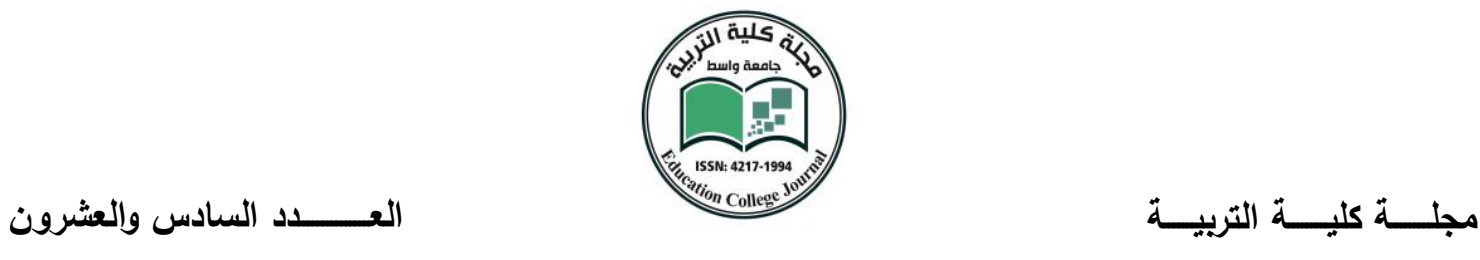

components of teaching, while the EFI focuses on reading the dialogue, listening to an audio with repetition.

7- Imitation and repetition, with a lot of tautology within the drills, prevail the general tone of the syllabus of EFI; notwithstanding, these are bases for the audio-visual approach, rather than a communicative one. EFI does not exceed a PPP, an audio lingual method of teaching, while IO follows a communicative, task based, content based and cooperative language learning, method of teaching.

8- Iraq Opportunities (IO) takes into consideration how students might think in English or build their thoughts using English, as students try to guess what the text is going to be about, and through task based learning.

9- As content based curriculum, with cross-curricular themes, each chapter in "Iraq Opportunities" texts, such as $4^{\text {th }}$ preparatory, is based on simplified general topic, ramifying more specific topics. This enables the student to talk about things which he already has a background about. But this hasn't been applied at the EFI.

10- EFI is mainly a PPP (Presentation, Practice and Production), structure-based curriculum. The prominent mode of teaching English in EFI is that of audiolingual approach, rather than the communicative approach. EFI fuses the four skills of teaching with slight focus on speaking, while IO works on teaching the four skills consecutively in relation to grammar and lexis.

11- EFI text is not economic at all since there is an exaggeration with presenting the pictures, which may fit a primary school pupils, the word list which is possible to be replaces by a mini-dictionary useful for the students, nonetheless, the dialogue transcripts are rewritten in the student's book and teacher's book, or made with quite long ones.

12- IO gives a wide range of possible answers for the students to make about the exercises; a student in many cases can give his answers due to his contentment; with EFI, the student is restricted to intended, untolerated answers. 


\section{Bibliography}

Berns, M. (2010) Concise Encyclopedia of Applied Linguistics. London: Elsevier Ltd.

Bussmann, H. (1996). Routledge Dictionary of Language and Linguistics. London: Routledge.

Edwards, C. and Willis, J. (2005). Teachers Exploring Tasks in English Language Teaching. London: Palgrave Macmillan.

Feez, S. (1998) Text-based syllabus design. Sydney: National Center for English Teaching and Research.

Gillies, R. M. , Ashman, A. F., Terwel, J. (2008). The Teacher's Role in Implementing Cooperative Learning in the Classroom. New York: Springer.

Harmer, J. (2001). The Practice of English Language Teaching. London: Longman.

Hyland, K. (2003). Second Language Writing. New York: Cambridge University Press.

Hyland, K. (2008). Genre and Academic Writing in the Discipline. (Language Teaching 41: 543562.

Johns, A. M. (2008). Genre Awareness for the Novice academic Students: An Ongoing Quest. Language Teaching 41(2): 237-252.

Johnson, D. \& Johnson, R. (2002). Learning together and alone: Overview and meta-analysis . Asia Pacific Journal of Education, 22, 95-105.

Messick, S. (1996). Validity and wash-back in language testing. Language Testing 13, 241-256.

Millar, D. (2011). Promoting Genre Awareness in EFL Classroom. English Teaching Forum. Volume 49: 3 - 10

Richards, J. and Rodgers, T. (2001) Approaches and methods in language Teaching. Cambridge: Cambridge University Press.

Richards, J. and Schmidt, R. (2002). Longman Dictionary of Language Teaching and Applied Linguistics. London: Longman.

Sandra, J. (2002). Interpreting Communicative Language Teaching. London: Yale University Press

Skehan, P. (1996) 'A framework for the implementation of task-based instruction' Applied Linguistics 17(1): 38-62.

Swales, J. (1990). Genre Analysis: English in Academic and research settings. Cambridge: Cambridge University Press. 
الأساليب المعتدلة في قبال الأساليب التقليدية في تعلم و تعليم اللغة الانكليزية لصفوف

الاعدادية في العراق

م.م :عباس عيدان عبيذ

\section{ملخص}

تستعرض الدراسة الحالية نظرة عامة لاهم العقبات التي تواجه تقدم العملية التزبوية فيما يخص منهاج

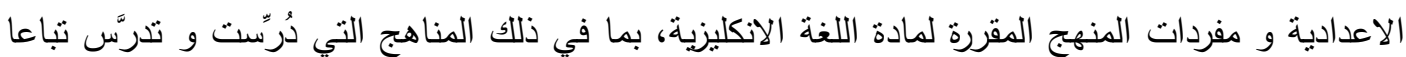

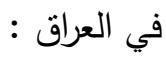

The new English Course in Iraq ( NECI), Iraq Opportunities (IO) and English for Iraq (EFI)

كما ان الدراسة تقدم تقصيلا عن اهم خصائص تلك المناهج و اقترانها مع طرق التدريس المنبعة

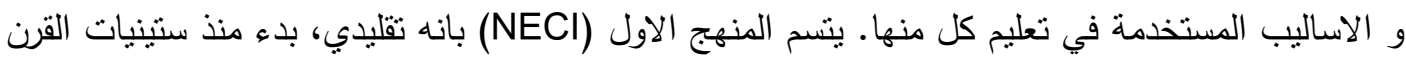

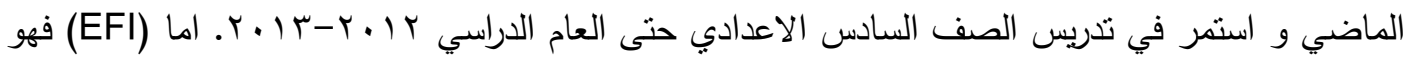
المقرر الذي حل محل (IO) ) و الذي تم المباثرة فيه للصف الخامس و السادس الاعدادي، و لم يفصح رسميا ايهما يستمر في الميدان التعليمي.

و من جانب آخر، فان الدراسة تتتاول اهم العقبات التي تواجه العطلية التعليمية كتفشي الملازم المساعدة للطالب و التي عملت على ان يزيغ الطلاب من مسار المنهج و الغاء عدة فعاليات تعليمية كاداء

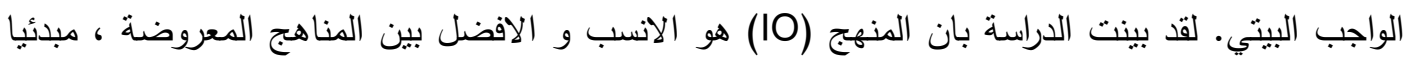
كونه مبني على طريقة تواصلية و اكثر تلائم للطبة في العراق.

ان النظام التعليمي العراقي، كما تقترح الدراسة، بحاجة ماسة الى اصلاح و تطوير و تخطيط افضل في البنية التزبوية و على جميع الاصعدة. 